\title{
Urethrocutaneous Fistula After Transobturator Tape Operation
}

\author{
(D) Alev ESERCAN ${ }^{a},{ }^{(0)}$ Tuncer BAHÇECI ${ }^{\text {b }}$ \\ ${ }^{a}$ Clinic of Gynecology and Obstetrics, Şanlıurfa Training and Research Hospital, Şanlıurfa, TURKEY \\ ${ }^{b}$ Clinic of Urology, Şanlıurfa Training and Research Hospital, Şanlıurfa, TURKEY
}

\begin{abstract}
The cause of urogenital fistulas can be surgical from either obstetric or gynecological. While its common presentation is continuous drainage of urine from the urinary system through the fistula, rarely it can be presented as an abscess. Our case was the first case of urethrocutaneous fistula after transobturator tape operation presented as an abscess. In this case report, an urethrocutaneous fistula developed in a 49-year-an old woman after a transobturator tape operation was mentioned. The fistula was treated with mesh removal and follow-up. In literature, our case is the first case of urethrocutaneous fistula after transobturator tape operation. In conclusion, urinary tract fistulas, which are rare, sometimes manifest themselves as abscesses. These cases can be solved by a high index of suspicion.
\end{abstract}

Keywords: Urethrocutaneous fistula; transobturator tape operation; stress incontinence

A urogenital fistula is an abnormal passage between the urinary tract and bladder, ureters, or urethra. This can occur between any of the structures of the pelvic region. As a result, this allows urine leakage through and out of the urogenital tract. This can result in deteriorating life quality so the effects of which may, in turn, have a negative impact on mental or emotional state, including an increase in social isolation. ${ }^{1}$

A recent meta-analysis estimated a pooled prevalence of 0.29 fistulae per 1,000 reproductiveage women in all regions with a rate of 1.6/1,000 in sub-Saharan Africa and 1.2/1,000 in south Asia. ${ }^{2}$

The etiology of urogenital fistulas is obstetric, surgical, radiation, malignant, and miscellaneous. As in developing countries, the most common etiology is obstetric, in developed countries gynecologic, urologic, or other pelvic surgery respectively.
Although symptoms of continuous urinary leakage suggest us a fistula, sometimes a fistula can be presented as an abscess like in our case. This case aimed to draw consideration to this uncommon occurrence.

\section{CASE REPORT}

A 49-year-old woman applied to the emergency room for a left swollen, painful, red area on the left groin side ten days after a transobturator tension-free vaginal tape (TOT) operation (Figure 1). An abscess was found out expanding from the labia majora to the thigh muscles on the left-hand side by laboratory and imaging studies (Figure 2a, 2b).

The abscess was drained and its content was compatible with urine. We gave $300 \mathrm{cc}$ methylene blue from the urinary catheter, leakage from the incision site of the abscess of the thigh was seen (Figure $3)$. There was no leakage from the vagina.

Correspondence: Alev ESERCAN

Clinic of Gynecology and Obstetrics, Şanlıurfa Training and Research Hospital, Şanlıurfa, TURKEY

E-mail: alevesercan@gmail.com

Peer review under responsibility of Journal of Clinical Obstetrics \& Gynecology. 


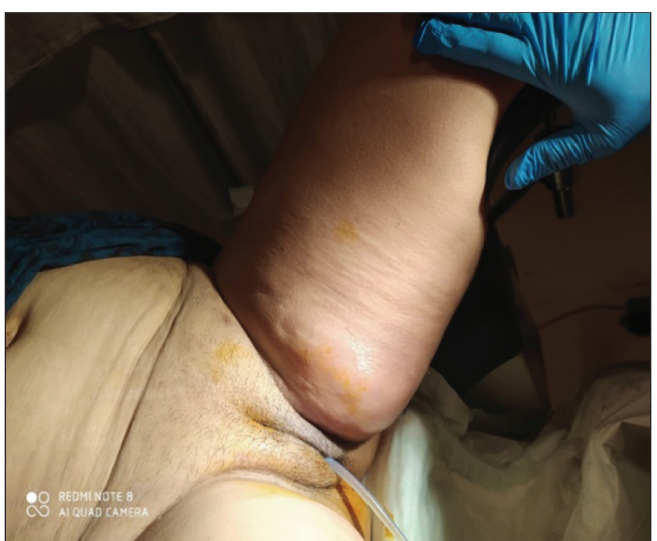

FIGURE 1: Abscess formation in the left groin area (asterisk).

In cystoscopy, while the bladder was detected to be normal, the mesh was found in the lower urethra causing an anterior urethral erosion (migration) (Figure 4).
The urologist removed the tension-free mesh completely. No need for suture was needed owing to a little defect and 20FR Foley urinary catheter was inserted for closure. After no leakage was seen in cystography, the urinary catheter was removed followed up by 2 weeks (Figure 5). Duloxetine treatment was used for stress urinary incontinence.

Consent: Written informed consent was obtained from the patient for publication of these images in urogynecology and any accompanying images.

\section{DISCUSSION}

One uncommon variant could be a urethrocutaneous fistula that will show as a thigh abscess emerging from different aetiological variables, including intrinsic or postoperative causes such as hypospadias
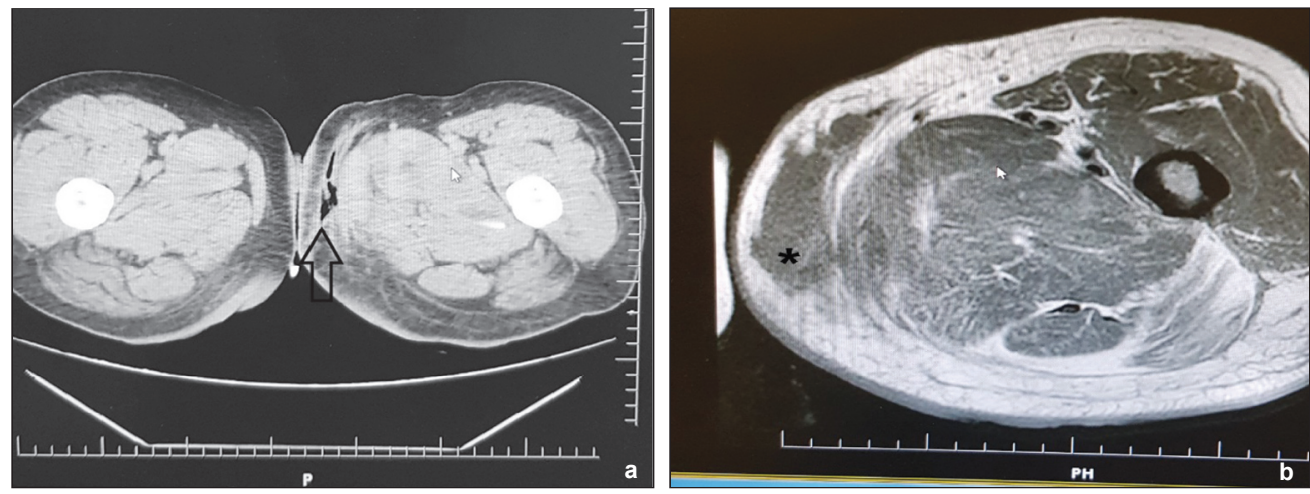

FIGURE 2: a) Pelvic axial computed tomography: Arrow; abscess formation (arrow) from labia majora to adductor muscle, b) Axial T2-weighted image: Asterisk; abscess formation (arrow) from the labia majora to the adductor muscles. Myositis can be seen in the hyperintense areas.

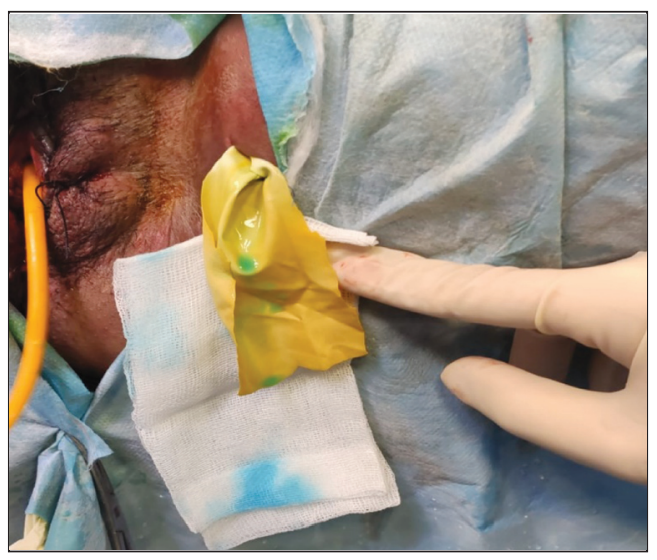

FIGURE 3: Leakage of methylene blue from drainage side on the thigh.

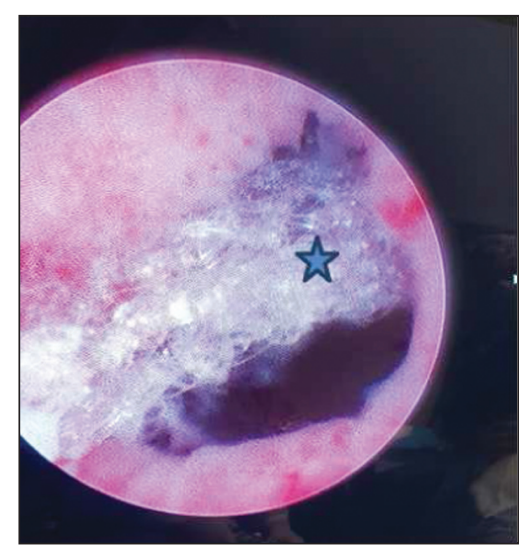

FIGURE 4: Tension-free mesh in mid-urethra (asterisk) 


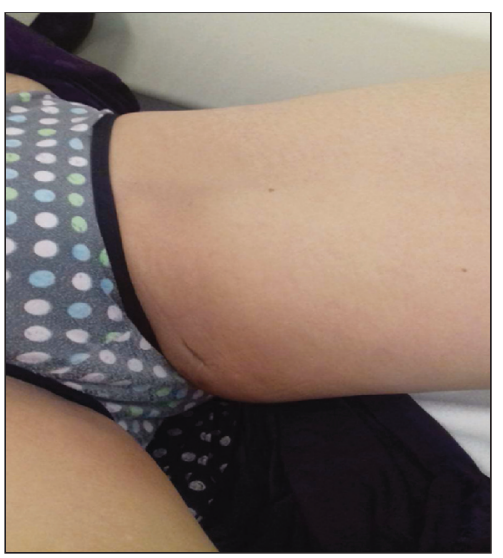

FIGURE 5: Postoperative result of fistula area

surgery and phalloplasty or metoidioplasty. ${ }^{3,4}$ The bladder has to be kept purge to dodge any increase in pressure or urine leak is vital to improve tissue healing. Our case was effectively treated with mesh excision, defect repair, and outpatient follow-up. In literature, our case is the first case of urethrocutaneous fistula after transobturator tape operation.

In conclusion, urinary tract fistulas, which are rare, sometimes manifest themselves as abscesses.
These cases can be solved by a high index of suspicion.

\section{Source of Finance}

During this study, no financial or spiritual support was received neither from any pharmaceutical company that has a direct connection with the research subject, nor from a company that provides or produces medical instruments and materials which may negatively affect the evaluation process of this study.

\section{Conflict of Interest}

No conflicts of interest between the authors and / or family members of the scientific and medical committee members or members of the potential conflicts of interest, counseling, expertise, working conditions, share holding and similar situations in any firm.

\section{Authorship Contributions}

Idea/Concept: Alev Esercan, Tuncer Bahçeci; Design: Alev Esercan; Control/Supervision: Alev Esercan, Tuncer Bahçeci; Data Collection and/or Processing: Tuncer Bahçeci; Analysis and/or Interpretation: Alev Esercan; Literature Review: Alev Esercan; Writing the Article: Alev Esercan, Tuncer Bahçeci; Critical Review: Tuncer Bahçeci; References and Fundings: Alev Esercan; Materials: Tuncer Bahçeci.

\section{REFERENCES}

1. Bodner-Adler B, Hanzal E, Pablik E, Koelbl H, Bodner K. Management of vesicovaginal fistulas (VVFs) in women following benign gynaecologic surgery: A systematic review and meta-analysis. PLoS One. 2017;12(2): e0171554. [Crossref] [PubMed] [PMC
2. Adler AJ, Ronsmans C, Calvert C, Filippi V. Estimating the prevalence of obstetric fistula: a systematic review and meta-analysis. BMC Pregnancy Childbirth. 2013;13:246. [Crossref] [PubMed] [PMC]

3. Nikolavsky D, Hughes M, Zhao LC. Urologic complications after phalloplasty or metoidioplasty. Clin Plast Surg. 2018;45(3):425-35 [Crossref] [PubMed]

4. Rohrmann D, Jakse G. Urethroplasty in female-to-male transsexuals. Eur Urol. 2003;44(5):611-4. [Crossref] [PubMed] 